\title{
Reassessing Coronary Artery Bypass Surgery Versus Percutaneous Coronary Intervention in Patients with Type 2 Diabetes Mellitus: A Brief Updated Analytical Report (2015-2017)
}

\author{
Xia Dai $\cdot$ Zu-chun Luo $\cdot$ Lu Zhai $\cdot$ Wen-piao Zhao $\cdot$ Feng Huang (iD
}

Received: August 15, 2018 / Published online: September 15, 2018

(C) The Author(s) 2018

\begin{abstract}
Introduction: In this analysis, we aimed to systematically compare percutaneous coronary intervention (PCI) versus coronary artery bypass surgery (CABG) in terms of adverse outcomes utilizing data from a recent (2015-2017) population of patients with type 2 diabetes mellitus (T2DM).

Methods: An electronic search of recent studies (2015-2017) was carried out using 'diabetes mellitus,' 'coronary artery bypass surgery,' and 'percutaneous coronary intervention' as the
\end{abstract}

Enhanced digital features To view enhanced digital features for this article go to https://doi.org/10.6084/ m9.figshare.7028390.

X. Dai · L. Zhai · W. Zhao

Department of Endocrinology, The First Affiliated Hospital of Guangxi Medical University, Guangxi, China

Z. Luo

Department of Internal Medicine Education, The First Affiliated Hospital of Guangxi Medical University, Guangxi, China

\section{F. Huang $(\bowtie)$}

Institute of Cardiovascular Diseases and Guangxi Key Laboratory Base of Precision Medicine in Cardio-cerebrovascular Disease Control and Prevention and Guangxi Clinical Research Center for Cardio-cerebrovascular Diseases, The First Affiliated Hospital of Guangxi Medical University, Guangxi, China

e-mail: huangfeng7925@163.com main search terms. Uncomplicated T2DM patients with stable coronary artery disease (CAD), left main CAD, and multi-vessel disease were included. RevMan software (version 5.3) was used to calculate odds ratios (OR) and 95\% confidence intervals (CIs).

Results: Among a total of 13,114 T2DM patients, CABG and PCI patients did not differ significantly in their rates of mortality (OR 0.90, 95\% CI $0.61-1.31 ; P=0.57)$ and cardiac death (OR 1.00, 95\% CI 0.78-1.30; $P=0.98$ ). However, rates of major adverse events, repeat revascularization, and myocardial infarction were significantly higher in the PCI group. Stroke rates did not significantly differ between the two groups.

Conclusion: Mortality (1-5 years) did not significantly differ between the CABG and PCI patients with T2DM. However, rates of other major adverse events were significantly higher in the PCI patients, suggesting that CABG is more advantageous than PCI in patients with T2DM.

Keywords: Coronary artery bypass surgery; Mortality; Percutaneous coronary intervention; Type 2 diabetes mellitus

\section{INTRODUCTION}

Several concerns have been raised by recently published meta-analyses

(2014-2015) 
comparing coronary artery bypass surgery (CABG) with percutaneous coronary intervention (PCI) in patients with type 2 diabetes mellitus (T2DM). For example, Bangalore et al. [1] recently published the results of a network meta-analysis, which led them to conclude that mortality following CABG was similar to that following PCI in patients with diabetes mellitus. However, Toeg et al. found that conclusion to be highly problematic and pointed to the results of their own meta-analysis [2]; in response, Bangalore et al. [3] defended their results and pointed out certain limitations of Toeg et al.'s meta-analysis. Aside from this particular controversial issue, other meta-analyses in this field have also reached divergent conclusions $[4,5]$.

Given this controversy as well as recent developments in interventional cardiology and the recent introduction of new guidelines for antiplatelet therapies (with new participants being treated based on those recent guidelines), in the work reported in the present paper, we aimed to systematically re-assess the important issue of whether PCI should be recommended over CABG or vice versa using data from the most recent cohort of T2DM patients (2015-2017).

\section{METHODS}

\section{Data Sources}

Only an electronic search was carried out (no manual search). The following databases were searched: MEDLINE (including PubMed); Cochrane Database; EMBASE database; Google Scholar; official websites of several common cardiology journals.

\section{Search Terms}

The main search terms were 'diabetes mellitus,' 'coronary artery bypass surgery,' and 'percutaneous coronary intervention.' Other terms searched for included 'coronary angioplasty,' 'cardiac surgery,' 'type 2 diabetes mellitus,' and abbreviations such as CABG and PCI.

\section{Outcomes}

The following outcomes (Table 1) were compared: mortality; myocardial infarction (MI); repeat revascularization (RR); stroke; major adverse events (MAEs), which refers to major adverse cardiac events and cerebrovascular events (including death, MI, RR, and/or stroke).

\section{Follow-up Periods}

The follow-up period varied from 1 to 5 years. However, most of the studies had a follow-up period of more than 3 years, as shown in Table 1.

\section{Data Extraction and Review}

The reviewers who were involved in the data extraction process were Xia Dai, Zu-chun Luo, Lu Zhai, Wen-piao Zhao, and Feng Huang. Data extracted included: type of study; total number of patients treated with CABG; total number of patients treated with PCI; year of publication (2015-2017); diseases of the participants; baseline features; outcomes and corresponding numbers of events; follow-up periods. Any disagreement was resolved by consensus.

The trials were assessed for risk of bias with reference to the Cochrane Collaboration [6]. Approximate grades of between $\mathrm{A}$ and $\mathrm{E}$ were allotted to the trials depending on their risk of bias; A corresponded to a low risk of bias, whereas $\mathrm{E}$ indicated a high risk.

\section{Statistical Analysis}

The software used for statistical analysis was RevMan version 5.3. The analytical parameters of most interest were the odds ratios (OR) with 95\% confidence intervals (CIs). Heterogeneity was assessed using two tests [6]:

(a) $Q$ statistic test: $P<0.05$ was considered to indicate a statistically significant result

(b) $I^{2}$ statistic test: the higher the percentage value of $I^{2}$, the greater the heterogeneity

In terms of the statistical model applied, a fixed effects model was used if $I^{2}$ was $<50 \%$, and a 
Table 1 Outcomes, diseases of the participants, and follow-up periods for each of the studies considered in this work

\begin{tabular}{llll}
\hline Study & Outcomes & Diseases of the participants & $\begin{array}{l}\text { Follow-up period } \\
\text { (years) }\end{array}$ \\
\hline Barber et al. [8] & MAEs, mortality, MI, stroke, RR & T2DM and MVD & 3.8 \\
Bangalore et al. [9] & MI, RR, mortality & T2DM and MVD & 4 \\
Ben-Gal et al. [10] & $\begin{array}{l}\text { MAEs, mortality, cardiac death, MI, RR, } \\
\text { stroke }\end{array}$ & $\begin{array}{l}\text { T2DM and MVD with } \\
\text { NSTEMI }\end{array}$ & 1 \\
Li et al. [11] & Mortality, MI, RR, stroke, MAEs & Diabetic nephropathy and & 4.3 \\
& & LMCAD & \\
Marui et al. [12] & Mortality, cardiac death, MI, stroke, MI, & T2DM and CAD \\
& RR & T2DM and MVD & 3.7 \\
Naito et al. [13] & Mortality, cardiac death & T2DM and CAD & 5 \\
Li et al. [14] & Mortality, MI, RR, stroke, MAEs & T2DM and ACS & 5 \\
Ramanathan et al. & Mortality, MI, RR, stroke, MAEs & & \\
[15] & & & 5 \\
\hline
\end{tabular}

MAEs major adverse events, $M I$ myocardial infarction, $R R$ repeat revascularization, $T 2 D M$ type 2 diabetes mellitus, $C A D$ coronary artery disease, NSTEMI non-ST segment elevation myocardial infarction, $M V D$ multi-vessel coronary disease, $L M C A D$ left main coronary artery disease, $A C S$ acute coronary syndrome

random effects model was used if $I^{2}$ was $>50 \%$. Sensitivity analysis was carried out using an exclusion method whereby multiple analyses were performed, with a different trial/observational study excluded in each analysis. Publication bias was assessed by observing the shape of the funnel plot.

\section{Compliance with Ethics Guidelines}

This meta-analysis is based on previously conducted studies and does not contain any studies with human participants or animals performed by any of the authors.

\section{RESULTS}

\section{Search Results and General and Baseline Features}

Figure 1 presents the study selection procedure for this analysis (the PRISMA guideline was

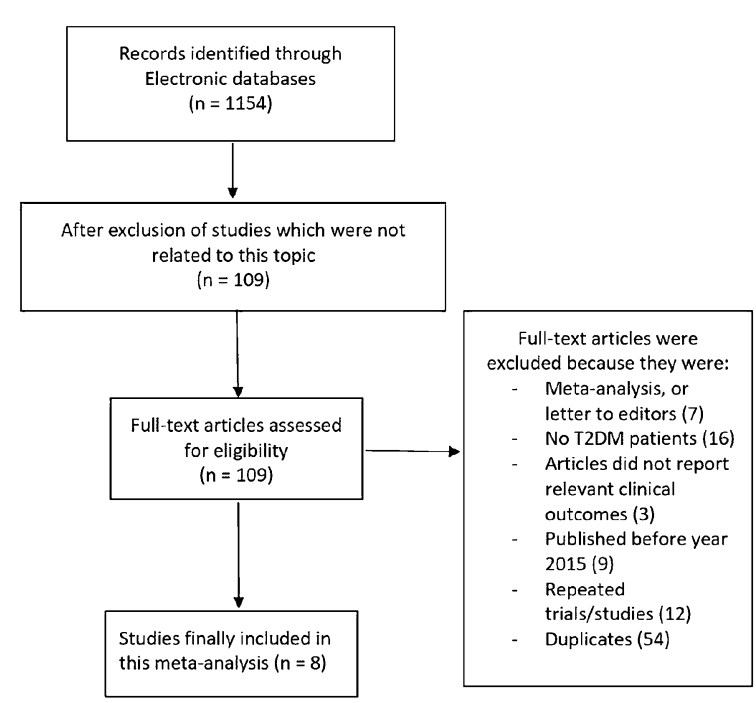

Fig. 1 Flow diagram showing the study selection process

followed [7]). Eight studies were ultimately included in the analysis [8-15].

A total of 13,114 patients with T2DM were included in this meta-analysis (5502 patients 
Table 2 General features of the studies included in the analysis

\begin{tabular}{llllc}
\hline Study & $\begin{array}{l}\text { Type of } \\
\text { study }\end{array}$ & $\begin{array}{l}\text { Year of } \\
\text { publication }\end{array}$ & $\begin{array}{l}\text { No. of patients treated with } \\
\text { CABG }(\boldsymbol{n})\end{array}$ & $\begin{array}{l}\text { No. of patients treated with } \\
\text { PCI }(\boldsymbol{n})\end{array}$ \\
\hline Barber et al. [8] & RCT & 2016 & 894 & 949 \\
Bangalore et al. [9] & OS & 2015 & 773 & 773 \\
Ben-Gal et al. [10] & RCT & 2015 & 423 & 1349 \\
Li et al. [11] & OS & 2017 & 53 & 46 \\
Marui et al. [12] & OS & 2015 & 861 & 1123 \\
Naito et al. [13] & OS & 2016 & 227 & 256 \\
Li et al. [14] & OS & 2017 & 406 & 406 \\
Ramanathan et al. & OS & 2017 & 1865 & 2710 \\
$\quad$ [15] & & & 7612 \\
Total no. of & & 5502 & \\
patients $(n)$ & & & \\
\hline
\end{tabular}

$R C T$ randomized controlled trial, $O S$ observational study, $C A B G$ coronary artery bypass surgery, $P C I$ percutaneous coronary intervention

Table 3 Baseline characteristics of the participants

\begin{tabular}{lllllll}
\hline Studies & $\begin{array}{l}\text { Age (years) } \\
\text { C/P }\end{array}$ & $\begin{array}{l}\text { Males (\%) } \\
\text { C/P }\end{array}$ & $\begin{array}{l}\text { HTN (\%) } \\
\text { C/P }\end{array}$ & $\begin{array}{l}\text { Ds (\%) } \\
\text { C/P }\end{array}$ & $\begin{array}{l}\text { Cs (\%) } \\
\text { C/P }\end{array}$ & Type of DES \\
\hline Barber et al. [8] & $64.1 / 64.8$ & $67.9 / 69.7$ & $87.7 / 87.9$ & $84.1 / 84.2$ & $14.6 / 13.6$ & DES \\
Bangalore et al. [9] & $64.7 / 64.9$ & $68.0 / 68.0$ & - & - & - & EES \\
Ben-Gal et al. [10] & $65.0 / 65.0$ & $73.0 / 66.3$ & $79.4 / 85.9$ & $61.8 / 72.7$ & $24.0 / 21.0$ & DES \\
Li et al. [11] & $71.5 / 72.9$ & $73.6 / 89.1$ & $88.7 / 91.3$ & $50.0 / 54.0$ & $67.9 / 41.3$ & DES* \\
Marui et al. [12] & $67.8 / 68.7$ & $73.0 / 68.0$ & $84.0 / 88.0$ & - & $25.0 / 25.0$ & DES \\
Naito et al. [13] & $72.7 / 72.7$ & $68.3 / 78.1$ & $74.0 / 77.0$ & $68.7 / 76.6$ & $62.6 / 58.6$ & DES \\
Li et al. [14] & $42.1 / 41.4$ & $89.2 / 94.3$ & $65.8 / 57.2$ & - & $62.1 / 72.8$ & DES \\
Ramanathan et al. [15] & $65.2 / 67.3$ & $73.2 / 72.0$ & $91.8 / 88.1$ & $79.5 / 77.5$ & - & DES \\
\hline
\end{tabular}

$C$ coronary artery bypass surgery, $P$ percutaneous coronary intervention, $H T N$ hypertension, $D s$ dyslipidemia, $C s$ current smokers, $E E S$ everolimus-eluting stents, $D E S$ drug-eluting stents, $D E S^{*}$ drug-eluting stents with the inclusion of a small percentage of bare metal stents

were treated with CABG and 7612 patients were treated with PCI), as shown in Table 2.

The baseline characteristics of the patients are presented in Table 3.

\section{Main Results of this Analysis}

This analysis-which only included trials and observational studies published after the year 2014-showed that during follow-up periods 


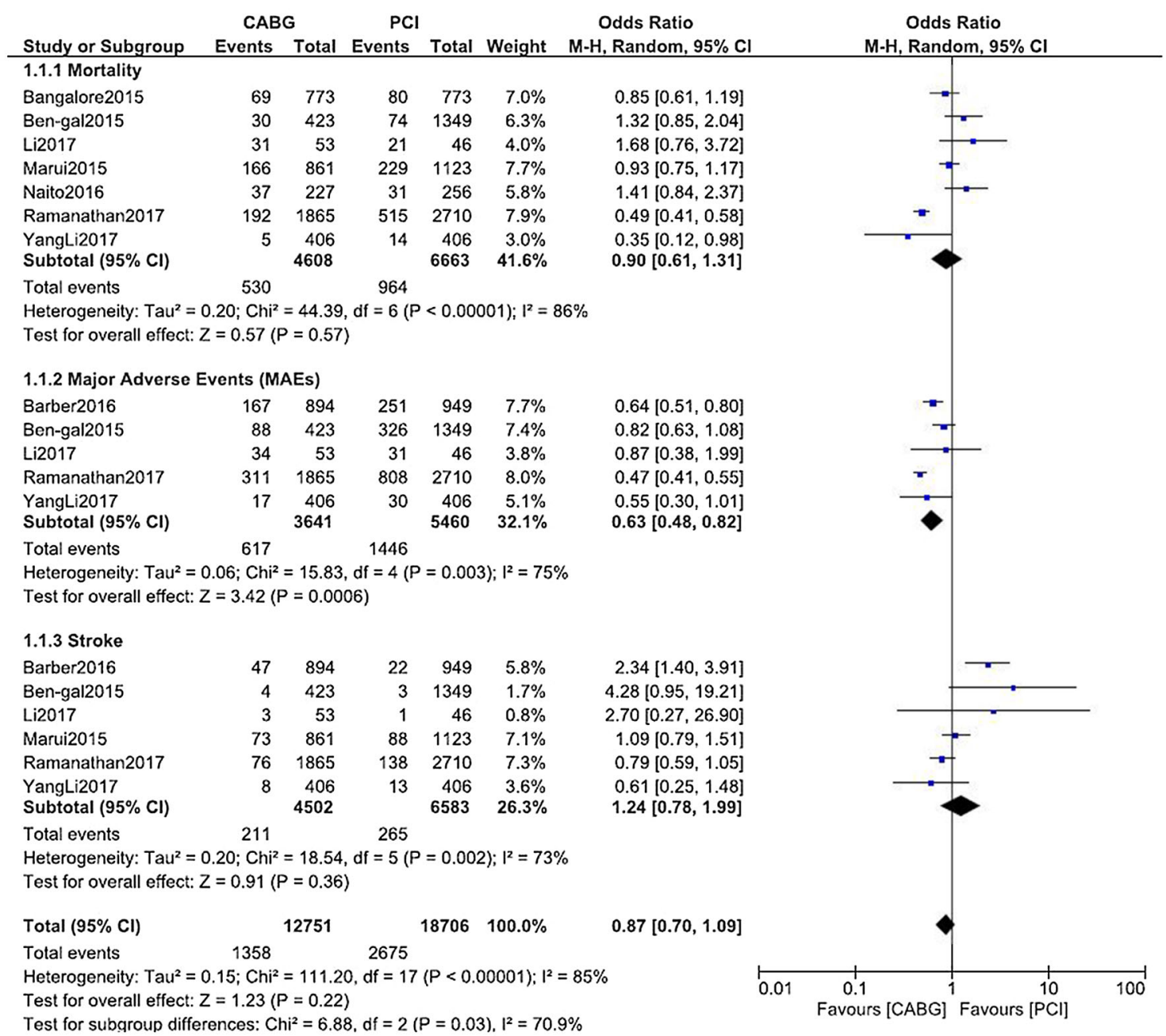

Fig. 2 Comparison of adverse outcomes in CABG versus PCI patients with T2DM (part I)

ranging from 1 to 5 years, mortality in T2DM patients treated with CABG was not significantly different from that in T2DM patients treated with PCI (OR 0.90, 95\% CI 0.61-1.31; $P=0.57$, as shown in Fig. 2). Stroke rates were also similar in the two groups (OR 1.24, 95\% CI 0.78-1.99; $P=0.36$ ). However, the rate of MAEs was significantly higher in the PCI group (OR $0.63,95 \%$ CI $0.48-0.82 ; P=0.0006$, as shown in Fig. 2).

The rates of cardiac death in the two groups were not significantly different (OR 1.00, 95\% CI $0.78-1.30 ; P=0.98)$. However, the rates of repeat revascularization and MI were significantly more favorable with CABG than with PCI (OR 0.27, 95\% CI 0.24-0.30; $P=0.00001$ and
OR $0.40, \quad 95 \% \quad$ CI $\quad 0.35-0.47 ; \quad P=0.00001$, respectively, as shown in Fig. 3).

When a sensitivity analysis was carried out, the results showed that the findings of this analysis were not excessively influenced by any of the studies. There was also little evidence of publication bias.

\section{DISCUSSION}

Recently, several issues have been raised as a result of comparisons of the adverse outcomes of CABG with those of PCI in patients with T2DM [1]. Mortality was reported to be similar in PCI and CABG patients with T2DM, which was seen as a problematic conclusion. 


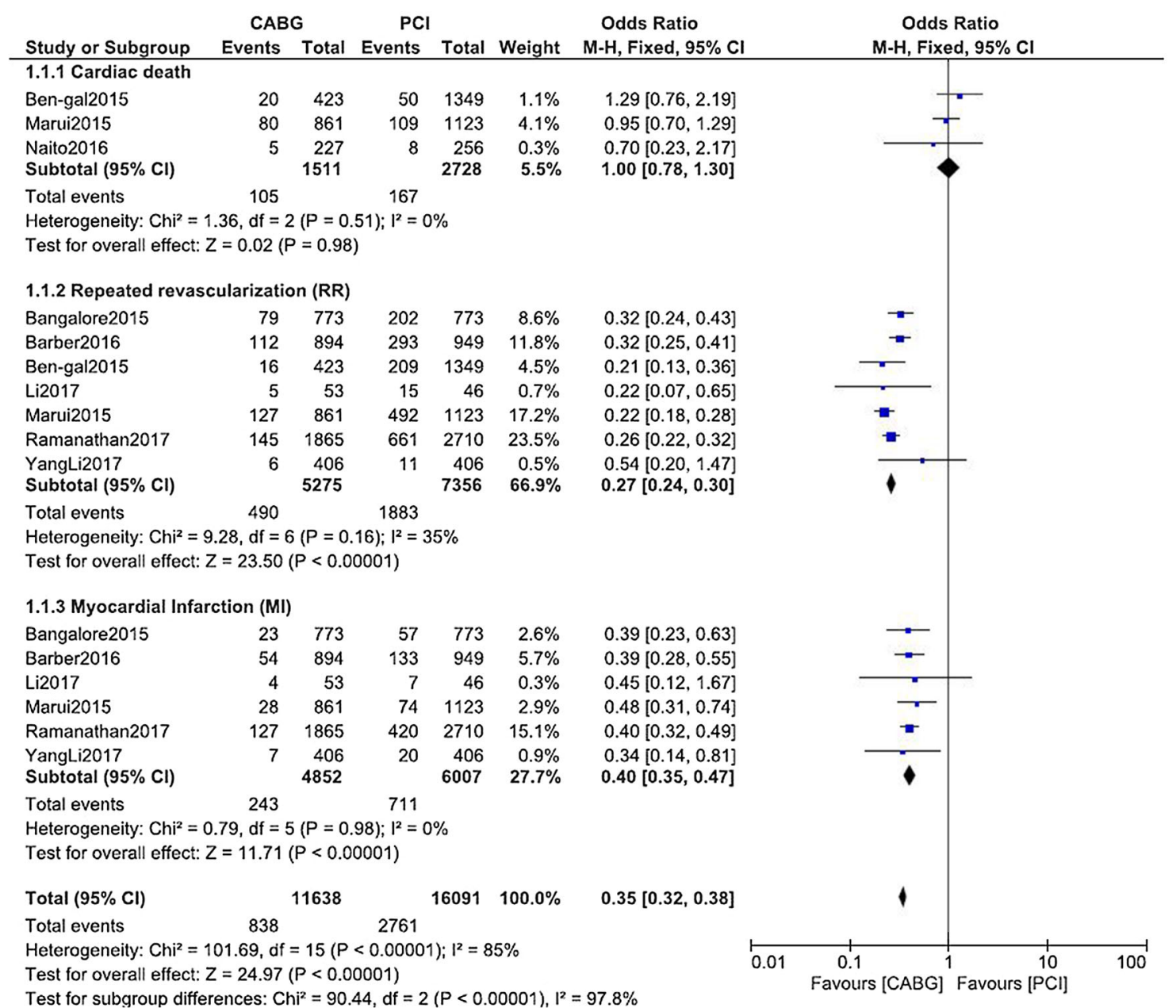

Fig. 3 Comparison of adverse outcomes in CABG versus PCI patients with T2DM (part II)

Therefore, in the present analysis, we recompared the outcomes of PCI and CABG using data from recently published studies of T2DM patients in order to check this conclusion.

The results of the present analysis show that during follow-up periods ranging from 1 to 5 years, all-cause mortality and the rate of cardiac death in T2DM patients treated with CABG were not significantly different from those in T2DM patients treated with PCI. However, the rate of MAEs (including MI and RR) was significantly higher with PCI. The difference in stroke rate between the groups was not statistically significant.

Patients with T2DM are more at risk of instent restenosis following PCI, even during a medium-term rather than long-term follow-up period, which contributes to the significantly higher MAE rate compared to T2DM patients treated with CABG. The incidence of both occlusive and nonocclusive re-stenosis has been shown to be higher in uncontrolled DM patients. Even if diabetes mellitus is independently associated with adverse outcomes following PCI, insulin treatment and the severity of this chronic disease may be other causes of adverse outcomes.

This analysis of newly published data supports the results obtained by Bangalore et al. [1], suggesting that their conclusion is not "problematic." Even though they carried out a network meta-analysis, which performed indirect comparisons, the results of the present analysis-which involved direct comparisons-did not show any significant difference from their results. 
A recent publication in Scientific Reports [16] also presented similar results to the current analysis, even though it did not specifically include patients with T2DM. No difference in mortality between patients treated with an everolimus-eluting stent (EES) and those treated with CABG was observed, whereas EES was associated with a significantly higher rate of major adverse cardiovascular events than CABG. In addition, in a study focusing on patients with multi-vessel coronary disease and severe left ventricular systolic dysfunction, long-term mortality in the PCI and CABG groups was comparable, whereas the PCI group was associated with significantly higher rates of $\mathrm{MI}$ and repeat revascularization [17].

Results of other studies in which a significantly higher mortality was associated with PCI in T2DM patients than with CABG in T2DM patients could be due to the use of insulin treatment, as previously stated [18].

Nevertheless, the selection of patients for CABG or PCI should be partly based on their SYNTAX scores, especially for patients with T2DM, since they may have other comorbidities. Even though CABG should be considered the optimal revascularization strategy, PCI could be more applicable to a few patients according to their SYNTAX scores. The application of the SYNTAX score in interventional cardiology should be encouraged [19].

\section{Limitations}

This study has a number of limitations. First, the total number of patients was not high enough to reach a definitive conclusion. Second, patient data from randomized trials and observational studies were combined and analyzed. Third, the follow-up periods varied between studies. Fourth, the diseases (e.g., left main coronary artery disease, multi-vessel disease, diabetic nephropathy) suffered by the participants varied. Finally, the data were adjusted to represent less heterogeneity.

\section{CONCLUSIONS}

During follow-up periods of 1-5 years, mortality in T2DM patients treated with CABG did not differ significantly from mortality in T2DM patients treated with PCI. However, the rate of other major adverse events was significantly higher in the CABG group compared to the PCI group.

\section{ACKNOWLEDGEMENTS}

Funding. This research was supported by the National Natural Science Foundation of China (nos. 81560046, 81760057) and the Guangxi Natural Science Foundation (no. 2016GXNSFAA380002). No funding was received for the publication of this article. The article processing charges were funded by the authors.

Authorship. All named authors meet the International Committee of Medical Journal Editors (ICMJE) criteria for authorship for this article, take responsibility for the integrity of the work as a whole, and have given their approval for this version to be published.

Authorship Contributions. Xia Dai, Zuchun Luo, Lu Zhai, Wen-piao Zhao, and Feng Huang were responsible for the conception and design of the study, data acquisition, analysis, and interpretation, the drafting the initial manuscript, and for revising it critically for important intellectual content. XD wrote and approved the final manuscript.

Disclosures. Xia Dai, Zu-chun Luo, Lu Zhai, Wen-piao Zhao, and Feng Huang have nothing to disclose.

Compliance with Ethics Guidelines. This meta-analysis is based on previously conducted studies and does not contain any studies with human participants or animals performed by any of the authors. 
Data Availability. All data generated or analyzed during this study are included in this published article.

Open Access. This article is distributed under the terms of the Creative Commons Attribution-NonCommercial 4.0 International License (http://creativecommons.org/licenses/ by-nc/4.0/), which permits any noncommercial use, distribution, and reproduction in any medium, provided you give appropriate credit to the original author(s) and the source, provide a link to the Creative Commons license, and indicate if changes were made.

\section{REFERENCES}

1. Bangalore S, Toklu B, Feit F. Outcomes with coronary artery bypass graft surgery versus percutaneous coronary intervention for patients with diabetes mellitus: can newer generation drug-eluting stents bridge the gap? Circ Cardiovasc Interv. 2014;7(4):518-25.

2. Toeg HD, Farkouh ME, Ruel M. Letter by Toeg et al regarding article "Outcomes with coronary artery bypass graft surgery versus percutaneous coronary intervention for patients with diabetes mellitus: can newer generation drug-eluting stents bridge the gap?". Circ Cardiovasc Interv. 2014;7(5):728.

3. Bangalore S, Toklu B, Feit F. Response to letter regarding article, "Outcomes with coronary artery bypass graft surgery versus percutaneous coronary intervention for patients with diabetes mellitus: can newer generation drug-eluting stents bridge the gap?". Circ Cardiovasc Interv. 2014;7(5):729.

4. Lim JY, Deo SV, Kim WS, Altarabsheh SE, Erwin PJ, Park SJ. Drug-eluting stents versus coronary artery bypass grafting in diabetic patients with multi-vessel disease: a meta-analysis. Heart Lung Circ. 2014;23(8):717-25.

5. Nicolini F, Agostinelli A, Vezzani A, Benassi F, Gherli T. CABG versus PCI in the treatment of diabetic patients affected by coronary artery disease. Int Heart J. 2014;55(6):469-73.

6. Higgins JP, Thompson SG, Deeks JJ, Altman DG. Measuring inconsistency in meta-analyses. BMJ. 2003;327(7414):557-60.

7. Liberati A, Altman DG, Tetzlaff J, Mulrow C, Gøtzsche PC, Ioannidis JP, Clarke M, Devereaux PJ,
Kleijnen J, Moher D. The PRISMA statement for reporting systematic reviews and meta-analyses of studies that evaluate healthcare interventions: explanation and elaboration. BMJ. 2009;339:b2700.

8. Baber U, Farkouh ME, Arbel Y, Muntner P, Dangas G, Mack MJ, Hamza TH, Mehran R, Fuster V. Comparative efficacy of coronary artery bypass surgery vs. percutaneous coronary intervention in patients with diabetes and multivessel coronary artery disease with or without chronic kidney disease. Eur Heart J. 2016;37(46):3440-7.

9. Bangalore S, Guo Y, Samadashvili Z, Blecker S, Xu J, Hannan EL. Everolimus eluting stents versus coronary artery bypass graft surgery for patients with diabetes mellitus and multivessel disease. Circ Cardiovasc Interv. 2015;8(7):e002626.

10. Ben-Gal Y, Mohr R, Feit F, Ohman EM, Kirtane A, $\mathrm{Xu} \mathrm{K}$, Mehran R, Stone GW. Surgical versus percutaneous coronary revascularization for multivessel disease in diabetic patients with non-ST-segmentelevation acute coronary syndrome: analysis from the Acute Catheterization and Early Intervention Triage Strategy trial. Circ Cardiovasc Interv. 2015;8(6):e002032.

11. Li HR, Hsu CP, Sung SH, Shih CC, Lin SJ, Chan WL, $\mathrm{Wu} \mathrm{CH}$, Lu TM. Percutaneous coronary intervention versus coronary artery bypass grafting in patients with diabetic nephropathy and left main coronary artery disease. Acta Cardiol Sin. 2017;33(2):119-26.

12. Marui A, Kimura T, Nishiwaki N, Mitsudo K, Komiya T, Hanyu M, Shiomi H, Tanaka S, Sakata R. Five-year outcomes of percutaneous versus surgical coronary revascularization in patients with diabetes mellitus (from the CREDO-Kyoto PCI/CABG Registry Cohort-2). Am J Cardiol. 2015;115(8):1063-72.

13. Naito R, Miyauchi K, Konishi H, Tsuboi S, Ogita M, Dohi T, Kajimoto K, Kasai T, Tamura H, Okazaki S, Isoda K, Yamamoto T, Amano A, Daida H. Comparing mortality between coronary artery bypass grafting and percutaneous coronary intervention with drug-eluting stents in elderly with diabetes and multivessel coronary disease. Heart Vessels. 2016;31(9):1424-9.

14. Li Y, Dong R, Hua K, Liu TS, Zhou SY, Zhou N, Zhang HJ. Outcomes of coronary artery bypass graft surgery versus percutaneous coronary intervention in patients aged 18-45 years with diabetes mellitus. Chin Med J (Engl). 2017;130(24):2906-15.

15. Ramanathan K, Abel JG, Park JE, Fung A, Mathew V, Taylor CM, Mancini GBJ, Gao M, Ding L, Verma S, Humphries KH, Farkouh ME. Surgical versus percutaneous coronary revascularization in patients 
with diabetes and acute coronary syndromes. J Am Coll Cardiol. 2017;70(24):2995-3006.

16. Bundhun PK, Pursun M, Teeluck AR, Bhurtu A, Soogund MZ, Huang WQ. Adverse cardiovascular outcomes associated with coronary artery bypass surgery and percutaneous coronary intervention with everolimus eluting stents: a meta-analysis. Sci Rep. 2016;6:35869.

17. Bangalore S, Guo Y, Samadashvili Z, Blecker S, Hannan EL. Revascularization in patients with multivessel coronary artery disease and severe left ventricular systolic dysfunction: everolimus-eluting stents versus coronary artery bypass graft surgery. Circulation. 2016;133(22):2132-40.

18. Bundhun PK, Wu ZJ, Chen MH. Coronary artery bypass surgery compared with percutaneous coronary interventions in patients with insulin-treated type 2 diabetes mellitus: a systematic review and meta-analysis of 6 randomized controlled trials. Cardiovasc Diabetol. 2016;15:2.

19. Bundhun PK, Sookharee Y, Bholee A, Huang F. Application of the SYNTAX score in interventional cardiology: a systematic review and meta-analysis. Medicine (Baltimore). 2017;96(28):e7410. 